\title{
Enhancing disease surveillance reporting using public transport in Dodoma District, Central Tanzania
}

\author{
L.E.G. MBOERA ${ }^{1 *}$, S.F. RUMISHA ${ }^{1}$, E.J. MWANEMILE², E. MZIWANDA², \\ \& P.K. MMBUJI ${ }^{1}$ \\ ${ }^{1}$ National Institute for Medical Research, P.O. Box 9653, Dar es Salaam, Tanzania \\ ${ }^{2}$ Dodoma District Council, P.O. Box 904, Dodoma, Tanzania
}

An efficient disease surveillance system is a prerequisite for an effective disease control programme. It is only when correct and timely reports about disease outbreaks reaches the responsible persons that prompt actions can be taken. Tanzania is in the process of strengthening its infectious disease surveillance system using an integrated approach. However, several constraints hamper the smooth implementation of the new strategy (Miller et al., 2003). Under the current Integrated Disease Surveillance and Response (IDSR) strategy, health facilities in Tanzania are required to immediately notify the district when they suspect an outbreak, and to provide week-ending reports for 7 outbreak-prone diseases, and monthlyreports for 13 priority diseases (Mboera, 2004).

Vital epidemiological information available at most health facilities in Tanzania are not often readily available for decision making at the district and national levels. This is due to lack of adequate information exchange facilities and systems that allow for a rapid access of information available at one level or both levels. Epidemiological reporting between facility and district levels of health delivery system has remained poor due to lack of effective and efficient means of communication (Miller et al., 2003; Kajeguka \& Mboera, 2003). In a recent study in 12 districts of Tanzania, the overall timeliness reporting from facility to district level was found to be $8 \%(0-19 \%)$ for weekly reports and 24\% (3-56\%) for montly reports (Gueye et al., 2005). Some routine paper reports are currently being picked up during supervision and outreach visits, but these visits are quite irregular. Some reports are sent by radio call and hard copies delivered in person. In this paper, we report the use of a participatory process in solving weekly epidemiological surveillance reporting problem in Dodoma Rural district in Tanzania.

Dodoma Rural District $\left(6^{\circ}, 30^{\prime}\right.$ to $8^{\circ} 0$ ' $\mathrm{S}, 35^{\circ}$, $30^{\prime}$ to $37^{\circ} 0^{\prime} \mathrm{E}$ ) is located in the central plateaus in Tanzania at an elevation of about $800-1200 \mathrm{~m}$ above sea level. The district consists of a number of mountain chains, between which are low-lying flat areas. A number of depressions are associated with these lower areas, which are generally waterlogged during the rainy season and have a tendency of salinity because of their limited outflow. The district has a dry Savannah type of climate characterised by a long dry season lasting between April and November. The average annual rainfall is 500$800 \mathrm{~mm}$, which is normally a short single wet season lasting between December and March. The district is made up of 8 divisions, 48 wards, and 128 villages covering an area of $14,004 \mathrm{~km}^{2}$. The district population is 495,176 made up of 96,686 households. The district is served by 81 health facilities ( 1 hospital, 6 health centres and 74 dispensaries). The nearest and furthest health facilities are $37 \mathrm{~km}$ and $145 \mathrm{~km}$ from the district capital, respectively (Mboera et al., 2005).

The participatory process approach involved researchers from the National Institute for Medical Research, district council health management team (CHMT) and the in-charges of all facilities in the district. The CHMT and health workers were trained to carry out problem-solving participatory approach in the area of communication. Following the discussions, strategies were developed and documented. Eighty-one health facilities were involved in the discussion in four different sessions. During the discussion several means of communication were suggested by the participants. These included: public bus transport, radio calls, passenger train, mobile phones and bicycles. The use of public buses was given the highest priority.

\footnotetext{
* Correspondence: L.E.G. Mboera; E-mail: lmboera@nimr.or.tz
} 
The discussions on the possibility of using public buses were later extended to involve bus owners, drivers, conductors and district government officials. with the bus owners and a consensus was reached that the district would make and install "drop-in" boxes (Figure 2) to be stationed at the bus terminals. The reports were then deposited by the bus

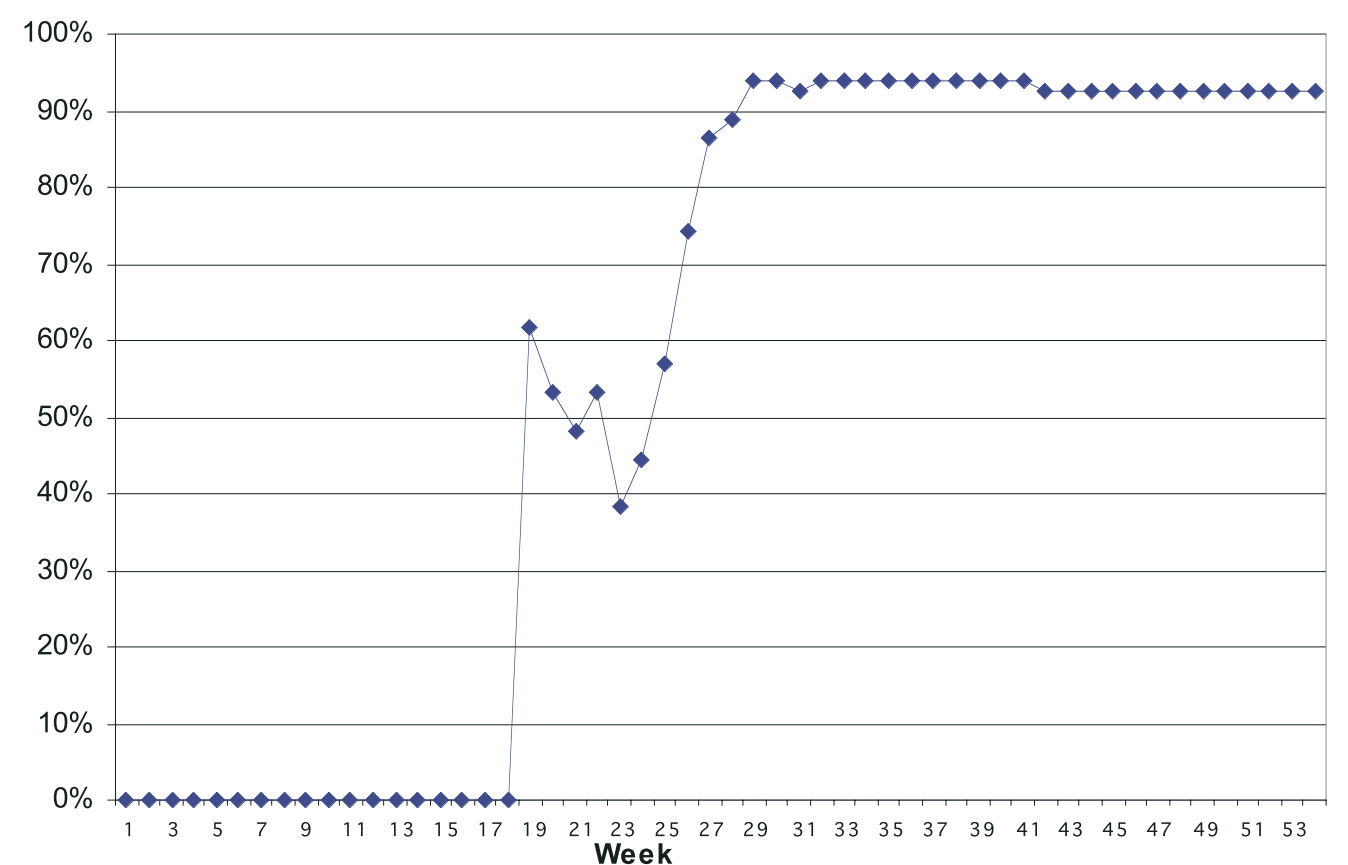

Figure 1: Percent of facility of timely reporting before and after the introduction of the new system at week 19 in 2004

Following the facility training, the CHMT met and sensitized bus owners, drivers and conductors on the need to assist health facilities in collecting and submitting weekly report to the district capital in Dodoma. The service was run smoothly for four weeks until week 23 when complaints were raised by the bus conductors of the fact that the bus terminals were far from the district office and therefore it would be wastage of time and money to continue with the service.

At week 23, there was a decrease from $62-38 \%$ of the number of facility reports received at the district office (Figure 1). The decrease was a result of few reports collected and submitted by the public buses. The CHMT met and discussed the problem conductors and collected by the district IDSR focal person or any other responsible officer from the district office. This was done and two "drop-in" boxes were made and placed at at Soko Kuu Majengo and Sabasaba bus terminals in Dodoma Municipality. In this case when the public buses reach the district capital the reports were deposited in the box and the bus continues with other activities. Twenty-four facilities (29.6\%) along Bahi Road and Dar es Salaam Road, were identified to be able to utilise the public transport service for submitting their weekly reports (Table 1).

In addition, to facilitiate weekly reporting for health facilities far from the two main roads, bicycles were 
Table 1: Health Facilities utilising public transport for weekly reporting in Dodoma

\begin{tabular}{cl}
\hline Soko Ku Majengo (Bahi road) & Sabasaba (Dar es Salaam Road) \\
\hline 1. Kigwe & 1. Chalinze \\
2. Nkondai & 2. Sagala \\
3. Bababu & 3. Majeleko \\
4. Kongogo & 4. Zajila \\
5. Zanka & 5. Mwitikila \\
6. Msisi & 6. Mpalanga \\
7. Chimendele & 7. Manchali \\
& 8. Ngahelezi \\
& 9. Lukali \\
& 10. Chilonwa \\
& 11. Chibelela \\
& 12. Manyenda \\
& 13. Iringa Mvumi \\
& 14. Mgunga \\
& 15. Dabala \\
& 16. Membe \\
& 17. Chiwondo \\
\hline
\end{tabular}

provided to the facilities. Some facilities along the main roads or those with radio calls were identified as satellite points. Weekly reports from remote facilities were submitted to the satellite facilities from where submission to the district was done. The source and satellite facilities and communication means are shown in Table 2.

With the introduction of the use of public transport and satellite system, weekly epidemiological reporting improved tremendously from $0 \%$ in week 18 to $62 \%$ in week 19 (Figure 2). Timely reporting reached and maintained at over 90\% from week 31 .

Timeliness and completeness are key indicators of a surveillance performance. These are defined as the proportion of expected reports received on time (timeliness) and the proportion of expected reports received (completeness). Reports are considered late if they have not been received by the established deadline (Gueye et al. 2005). Recent analyses of the infectious disease surveillance system in Tanzania have revealed weaknesses in communication systems and hence reporting of epidemiological surveillance (Nsubuga et al., 2001; Miller et al., 2003; Mboera et al., 2004). An effective epidemiological surveillance in Tanzania is therefore, hampered by lack of reliable and efficient communication systems. To improve communication, the use of information communication technology in surveillance needs to be emphasised and improved. However, this requires capital investment and it will take time before it can be full utilised in resource-poor countries such as Tanzania. Nonetheless, problem solving using participatory approach may provide immediate solutions as has been observed in this study. 
Table 2: Use of satellite facilities in weekly reporting in Dodoma

\begin{tabular}{lll}
\hline Source Facility & Satellite Facility & Means of communication \\
\hline Lukali & Lamaiti & Radio call \\
Makanda & Lamaiti & Radio call \\
Mkondai & Mundemu & Radio call \\
Msisi & Mundemu & Radio call \\
Zanka & Mundemu & Radio call \\
Mpwayungu & Huzi & Radio call \\
Nkambaku & Huzi & Radio call \\
Chinungulu & Manda & Radio call \\
Ilangali & Manda & Radio call \\
Bahi-Mission & Bahi & Radio call/ bus service \\
Mkola & Bahi & Radio call/ bus service \\
Ibiwa & Bahi & Radio call / bus service \\
Chenene & Haneti & Radio call/ bus service \\
Gwandi & Haneti & Radio call/ bus service \\
Humekwa & Haneti & Radio call/ bus service \\
Igandu & Handali & Radio call \\
\hline
\end{tabular}

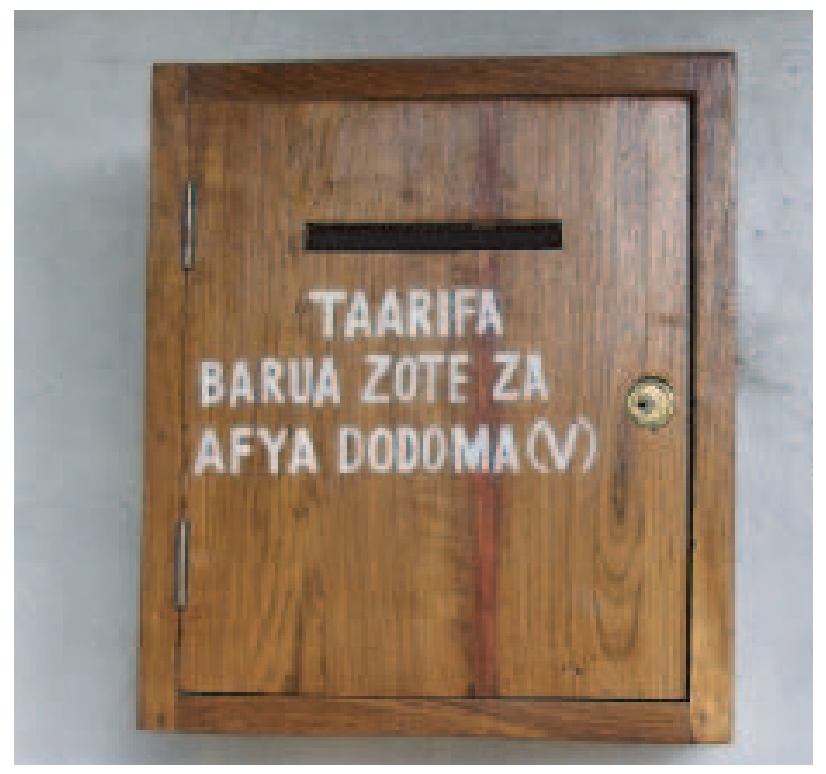

Figure 2: A box for collection of weekly report at Soko-Kuu Majengo bus terminal in Dodoma

It is essential to strengthen communication systems at all levels so that data collected is submitted to relevant authorities in a timely manner. The involvement of district level and facility level health workers in participatory approaches improved their performance in disease surveillance in the district. In conclusion, linking the integrated disease surveillance and response strategy beyond the health system through the involvement of various stakeholders is likely to improve disease surveillance implementation in the country.

\section{References}

Gueye, D., Senkoro, K.P. \& Rumisha, S.F. (2005) Monitoring and Evaluation of Integrated Disease Surveillance and Response in Tanzania, October-December 2003. Bethesda, MD: The Partners for Health Reformplus, Abt Associates Inc.

Kajeguka, A.C. \& Mboera, L.E.G. (2003) Information and communication technology: options for strengthening integrated disease surveillance and response at district level in Tanzania. Tanzania Health Research Bulletin 5, 61-67.

Mboera, L.E.G. (2004) Disease surveillance in Tanzania: an integrated approach in the management and control of communicable diseases. Proceedings of the $19^{\text {th }}$ Annual Joint Scientific Conference, Arusha, Tanzania, March 15-17, 2004.

Mboera, L.E.G., Rumisha, S.F., Senkoro, K.P., Kamugisha, M.L. \& Kitua, A.Y. (2004) 
East African Integrated Disease Surveillance Network 2001-2004. Technical Report submitted to the Rockefeller Foundation. National Institute for Medical Research, Dar es Salaam, Tanzania

Mboera, L.E.G., Rumisha, S.F., Senkoro, K.P., Mayala, B.K., Shayo, E.H \& Kisinza, W.N. (2005) Determination of strategies and approaches for a successful improvement of gaps for health knowledge in Tanzania. National Institute for Medical Research, Dar es Salaam, Tanzania, August 2005.

Miller, L.F., Fields, R., Mmbuji, P.K.L., Posner, S., Mboera, L.E.G., Jimmerson, A., Senkoro,
K.P., Rumisha, S.F., Shayo, E.H. \& Mwami, J.A. (2003) Situation Analysis of Infectious Disease Surveillance in two Districts in Tanzania, 2002. Bethesda, MD: The Partners for Health Reformsplus Project, Abt Associates Inc.

Nsubuga, P., Eseko, N., Wuhib, T., Ndayimirije, N., Chungong, S. \& McNabb, S. (2002) Structure and performance of infectious disease surveillance and response, United Republic of Tanzania, 1998. Bulletin of the World Health Organization 80, 196-202. 